\title{
Optimization Method of Reducing the Differential Settlements of Piled Raft Foundations Based on Pile-to-Pile Interaction Theory
}

\author{
Yunfei Xie ${ }^{1,2}$ and Shichun Chi (iD ${ }^{1,2}$ \\ ${ }^{1}$ State Key Laboratory of Coastal and Offshore Engineering, Dalian University of Technology, Dalian, China \\ ${ }^{2}$ Faculty of Infrastructure Engineering, Dalian University of Technology, Dalian, China \\ Correspondence should be addressed to Shichun Chi; schchi@dlut.edu.cn
}

Received 4 December 2019; Revised 12 July 2020; Accepted 23 July 2020; Published 10 August 2020

Academic Editor: Filippo Ubertini

Copyright ( ) 2020 Yunfei Xie and Shichun Chi. This is an open access article distributed under the Creative Commons Attribution License, which permits unrestricted use, distribution, and reproduction in any medium, provided the original work is properly cited.

\begin{abstract}
In order to reduce the differential settlement of piled raft foundations, an optimization method based on pile-to-pile interaction theory is proposed in this paper, which translates the problem of pile-to-pile interaction (PPI) in pile groups into that in single piles using the interaction factor method. The pile lengths were adjusted via the relationship between load, settlement, and the length of single piles during the optimization design. ANSYS software, in conjunction with nonlinear elastic soil model, is used to analyze piled raft foundation models. Two cases with different safety factors that suffer different kinds of surface loads (uniform load and nonuniform load) are used to verify this method. The differential settlements of the raft in different cases are all reduced by nearly or more than $80 \%$ after optimization design. The results show that the optimization method proposed in this paper has high efficiency and stability. This study can help practicing engineers optimize the pile lengths in pile groups to satisfy higher differential settlement requirements.
\end{abstract}

\section{Introduction}

Piled raft foundations (PRFs) have been used for many years as a method of transmitting the loads from the superstructure to competent strata at depth in the ground. During the traditional design of pile foundations, a large safety factor is always used to control the settlements and differential settlements. The stiffness distribution of the pile group is always uniform for the convenience of design and construction. However, with the gradual improvement of building requirements for the control of settlement and differential settlement, it is very wasteful to meet the requirements by increasing the safety factor for the reason that pile-to-pile interaction and pile-soil-pile interaction always exist in PRFs [1-3]. More recently, the focus has shifted towards more economical and reasonable design, thereby prompting considerable research effort to optimize the piles in the group.

Optimization design of PRFs with dissimilar piles (with different lengths and diameters) $[4,5]$ and pile arrangement
[6] has drawn much attention in recent years, which can minimize the differential settlement on top of the pile group and rearrange the load distribution of a PRF. The critical design criteria are often associated with the differential settlements especially for large pile groups and important buildings [7-11]. To address this issue, Padfield and Sharrock [12] enhanced pile group performance by changing the pile arrangements across the group. Nguyen et al. [13, 14] gave a parametric study for the optimal design of large PRFs on sand, and the results show that differential settlement could be effectively reduced by putting more piles in the center of a raft than in other areas. Leung et al. [15] gave an analysis and optimization method for PRFs which allows the coupling of the stiffness of superstructure with the foundation model. Algin [16] carried out a multiobjective optimization analysis method using the response surface method (RSM) to achieve the most economical design solution that satisfies the present design constraints for JGRs.

These aforementioned studies, however, have some limitations in the convenience of the application of 
optimization methods and the accuracy of optimization results. Pile layout optimizations proposed via outwardly powerful and inwardly weak or outwardly weak and inwardly powerful are easy to achieve, but the accuracy of optimization results is difficult to control. Optimization designs based on traditional gradient methods or genetic algorithm methods can easily result in accurate optimization results, but they are restricted to design problems that they must be mathematically formulated and differentiable and need expensive computation (especially for large-scale pile groups). In the view of construction convenience, variable pile length is undoubtedly the least difficult way compared with the design using variable pile diameter and variable pile spacing because it avoids the increase of positioning complexity caused by different pile spacing and the constructing trouble caused by different pile diameters. In order to achieve a variable stiffness optimization design using different pile lengths, it is necessary to clarify the "load-settlement-pile length" $(L-S-P)$ relationship of pile groups. It is easy to establish $L-S-P$ mathematical relationship for a single pile, but difficult for pile groups. Therefore, the key of this paper is how to transform the problems in pile group optimization into the optimization problems among single piles combined with PPI, to achieve the optimization design with dissimilar pile length (PPI optimization method).

An important result of research into the settlement behavior of pile foundations under vertical loads is that predictions only based on elastic theory are excessively conservative, and since the surrounding soil is always assumed to be single phase, the consolidating pile-head settlement is often neglected when a pile foundation is located in deep and saturated soil [17]. Therefore, nonlinear soil behavior is considered to be governed by Duncan-Chang (DC) model [18] in this paper. Within a nonlinear framework, pile settlement is coupled with the ultimate capacity, and therefore, an accurate estimation of a pile capacity is a prerequisite for a rigorous analysis of the serviceability limit state. While simplified design approaches an integral part of preliminary foundation design, three-dimensional (3D) nonlinear continuum analyses are becoming more commonplace. Therefore, 3D finite element method (FEM) is used to estimate the bearing capacity of single piles and the loads shared by each pile in the groups. Through the relationship of the settlement of single piles and that in pile group, which is established in the PPI optimization method, each pile length can be adjusted according to the corresponding pile top settlement of the pile group. High calculation cost and too much iteration times are avoided during this process. The optimization results show that the differential settlements of the pile groups in different cases can be highly reduced after optimization design compared with the traditional design no matter what the load is uniform or nonuniform.

\section{Method}

Based on the verification of the simulation of a single pile load test via FEM, the single pile load-settlement $(L-S)$ curve and the ultimate bearing capacity (UBC) in different pile lengths with the same soil can be estimated. The $L-S-P$ surface of single piles is obtained via interpolating the $P-S$ curves of several single piles with MATLAB. The required pile length can be determined by any given pile top load $P_{i}$ and the corresponding settlement $S_{i i}$ of single pile via $L-S-P$. However, $L-S-P$ is only used for single pile settlement problems because it neglects the complex influence in pile groups. Therefore, $L-S-P$ cannot be applied to the optimization design of pile group directly, and a relationship between pile group and single piles is necessary to be established.

2.1. Establishment of Pile-to-Pile Influence Coefficient $\left(\beta_{i j}\right)$ in Pile Groups. PPI effects, which especially exist between pile shafts, necessitate rigorous treatment, as settlements are amplified compared with single pile values $[19,20]$. This necessitates more reliable modelling of the development of pile-soil interface resistance during loading as well as more realistic treatment of PPI $[21,22]$.

2.1.1. Introduction of PPI Factors. The interaction factor method (IFM) $[23,24]$ is used for accounting PPI in the design of pile groups. Interaction factor $\alpha_{i j}[25,26]$ for pile $i$ due to pile $j$, corresponding to the spacing between piles $i$ and $j$, is given as follows:

$$
\alpha_{i j}=\frac{\Delta S_{i j}}{\Delta S_{i i}}=\frac{S_{i j} / P_{j}}{S_{i i} / P_{i}}=\frac{P_{i}}{P_{j}} \times \frac{S_{i j}}{S_{i i}},
$$

where $S_{i i}$ is the settlement of a single pile $i$ under its own load $\left(P_{i}\right) ; \Delta S_{i i}=S_{i i} / P_{i}$ is the settlement of a single pile $i$ under unit load; $S_{i j}$ is the additional settlement of pile $i$ due to adjacent pile $j$ loaded by $P_{j}$; and $\Delta S_{i j}=S_{i j} / P_{j}$ is the additional settlement of pile $i$ due to adjacent pile $j$ loaded by unit load. The total settlement of pile $i$, which satisfies the principle of superposition, is the sum of its own settlement $\left(S_{i i}\right)$ and additional settlement $\left(S_{i j}\right)$ due to pile $j$ [27]:

$$
S_{i}=S_{i i}+S_{i j}
$$

\subsubsection{Application of PPI Factor in Pile Groups. Some re-} searchers consider that the use of interaction factors based only on the spacing of any pair of piles in a group may result in ignoring the potential reinforcing effects of center piles [28-31]. From this view, the principle of superposition is not valid in nonlinear engineering problems. Nevertheless, some other research [32] shows that the soil remains in a linear elastic state outside this narrow region near the pile-soil interface. Therefore, PPI is governed by the elastic behavior in this paper.

Superposition of two-pile interaction factors is used to predict full pile group behavior. In this method (referring to Figure 1), the settlement $S_{i}$ of pile $i$ within a group of $N$ piles can be obtained by the IFM, which is given as follows [27]: 


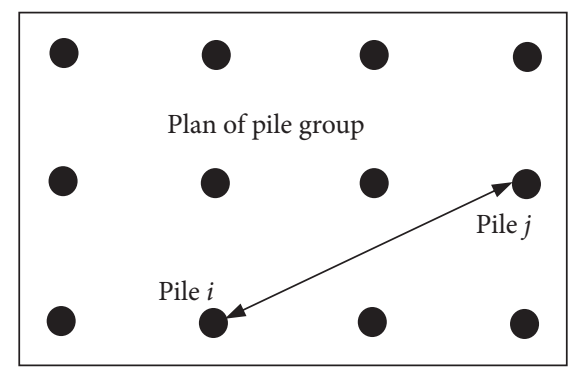

FIgURE 1: Superposition via the IFM.

$$
S_{i}=\sum_{j=1}^{j=N} P_{j} \frac{S_{i i}}{P_{i}} \times \alpha_{i j}=S_{i i} \sum_{j=1}^{j=N} \frac{P_{j}}{P_{i}} \times \alpha_{i j}=S_{i i} \beta_{i}
$$

where

$$
\beta_{i}=\sum_{j=1}^{j=N} \frac{P_{j}}{P_{i}} \times \alpha_{i j}=\sum_{j=1}^{j=N} \frac{P_{j}}{P_{i}} \times \frac{P_{i}}{P_{j}} \times \frac{S_{i j}}{S_{i i}}=\frac{\left(\sum_{j=1}^{j=N} S_{i j}\right)}{S_{i i}}=\frac{S_{i}}{S_{i i}} .
$$

$\beta_{i}$ is defined as the total influence on pile $i$ affected by the other piles in the pile group. Similarly, there is $\beta_{j}=S_{j} / S_{j j}$. The influence coefficient of pile $j$ on pile $i$ in the pile group is defined as follows:

$$
\beta_{i j}=\frac{\beta_{i}}{\beta_{j}}=\frac{\left(S_{i} / S_{i i}\right)}{S_{j} / S_{j j}}=\frac{\left(S_{i} / S_{j}\right)}{S_{i i} / S_{j j}} .
$$

Equation (5) shows that the influence coefficient between any two piles in the pile group can be expressed by the single pile settlements of the two piles and the settlements of the two piles in a pile group under the same load condition. This paper assumes that the $\beta_{i j}$ only depends on the spacing between piles $i$ and $j$ and will not change with the change of pile length.

\subsection{PPI Optimization Method}

2.2.1. Optimization Design Based on $\beta_{i j}$. In order to solve the differential settlement problem in a PRF caused by pile-soil interaction and different loads on top of the piles, variable pile lengths are used in this paper to decrease the differential settlement. The parameters with "' are defined as the optimization target parameters. For example, $S_{i i}^{\prime}$ and $S_{i}^{\prime}$ are the target settlement of a single pile $i$ and the target settlement of pile $i$ in a pile group, respectively.

The reference pile (R-pile) needs to be determined at first, and the other piles are optimized with the settlement of $\mathrm{R}$-pile as the reference line. Therefore, if pile $j$ is chosen as the R-pile, there is $S_{j j}=S_{j j}^{\prime} . S_{i}^{\prime}=S_{j}^{\prime}=S_{j}$ for any pile $i$ in the pile group. The influence coefficient is unchanged because of the unchanged pile spacing during the optimization procedure, and therefore, $\beta_{i j}^{\prime}=\beta_{i j}$ is given by

$$
\beta_{i j}^{\prime}=\frac{\left(S_{i}^{\prime} / S_{j}^{\prime}\right)}{S_{i i}^{\prime} / S_{j j}^{\prime}} \Longrightarrow \beta_{i j}^{\prime}=\frac{1}{\left(S_{i i}^{\prime} / S_{j j}^{\prime}\right)} \Rightarrow \frac{1}{\left(S_{i i}^{\prime} / S_{j j}\right)}=\beta_{i j} \Longrightarrow S_{i i}^{\prime}=\frac{S_{j j}}{\beta_{i j}}
$$

Equation (6) shows that the target single pile settlement of any pile $i\left(S_{i i}{ }^{\prime}\right)$ can be obtained through the single pile settlement $\left(S_{j j}\right)$ of R-pile and the influence coefficient $\left(\beta_{i j}\right)$ of pile $i$ due to R-pile. The influence coefficients of R-pile on other piles in the pile group are different and can be expressed as matrix $[\beta]_{R}$. The target settlement $\left(S_{i i}{ }^{\prime}\right)$ of each single pile is also different and can be expressed as matrix $[S]_{t}$. Therefore, equation (6) can be expressed as follows:

$$
[S]_{t}=\frac{S_{j j}}{[\beta]_{R}} .
$$

The length of each pile $([L])$ in the pile group after optimization design can be obtained with $[S]_{t},[P]$, and $L-S-P$ surface.

2.2.2. Calculate $[\beta]_{R}$. The load distribution on top of piles in a pile group is affected by raft stiffness. Even if the load is uniform, the load can be unevenly distributed on top of the piles due to the pile-soil interaction. Moreover, the load distribution mechanism of pile top under uneven load is more complex. Therefore, it is difficult to calculate $[S]_{t}$ directly. In order to solve this problem, a PRF system is established using 3D FEM, which considers the influence of pile group effect and raft stiffness on load distribution. After analysis of the PRF system, the loads $([P])$ and settlements $\left([S]_{\text {group }}=\left[S_{1}, \ldots, S_{i}, \ldots, S_{N}\right]\right)$ on top of the piles can be extracted directly, and then, the settlements of single piles $\left([S]_{\text {single }}=\left[S_{11}, \ldots, S_{i i}, \ldots, S_{N N}\right]\right)$ under corresponding loads $([P])$ can be extracted by $L-S-P$ surface. Finally, each influence coefficient $\left(\beta_{i j}\right)$ can be obtained by equation (5).

2.3. Optimal Iteration. Optimization efficiency can be improved by recycling the PPI optimization method. After the $m_{\text {th }}$ iteration, the load distribution $\left([P]_{m}\right)$, settlements of the piles $\left([S]_{\text {group }, m}\right)$, and pile lengths $\left([L]_{m}\right)$ of the optimized model are extracted, and the corresponding $[S]_{\text {single, } m}$ can be obtained. Then, renew $[\beta]_{R}$ and $[S]_{t}$ by equations (5) and (7). Finally, the new pile lengths $\left([L]_{m+1}\right)$ are obtained by $L-S-P$ surface, where $m$ represents the number of iterations and $m=0$ in the initial design.

The different optimized pile lengths need to be merged and combined after optimization design, and the error will always exist. Therefore, this paper agrees that if the increment $\left(\Delta \mathrm{FF}_{m+1}=\mathrm{FF}_{m+1}-\mathrm{FF}_{m}\right)$ of optimum rate $(\mathrm{FF})$ of differential settlement is less than $5 \%$, the optimization effect tends to be stable and the optimization cycle can be stopped. FF represents the optimization rate and is defined as follows:

$$
\mathrm{FF}=\frac{R-R^{\prime}}{R}
$$


where $R$ is the variable of the initial design and $R^{\prime}$ is that of the optimized design.

2.4. Suggestions and Constraint Condition. The corresponding SF in a different initial design will produce a different differential settlement. In order to reduce the differential settlement more effectively, this paper assumed that there is a linear correlation between the maximum settlement of the pile group and the corresponding safety factor (SF) as shown in Figure 2, and three suggestions about the selection of R-pile are given as follows:

(a) When $\mathrm{SF} \geq 2$, it belongs to conservative design and means that the optimization space of the PRF is sufficient. It is suggested that the pile with the largest settlement should be taken as R-pile, and the whole optimization design is mainly to reduce the length of piles.

(b) When $\mathrm{SF} \leq 1$, it belongs to the low safety factor design. The pile with the smallest settlement should be taken as R-pile, and the optimization design is mainly to increase the length of piles.

(c) When $1<\mathrm{SF}<2$, the pile corresponding to the moderate settlement is taken as R-pile, and the length of the piles can be increased or reduced at the same time in the whole optimization design. The pile corresponding to this settlement ( $S$ in Figure 2 ) is taken as the R-pile.

In this paper, the SF is defined as the UBC of the pile groups divided by an applied load as shown in equation (9), and it depended on the initial design of the PRF (e.g., the pile length, pile diameter, and pile configuration). In order to facilitate the calculation, the load component of raft [33] is not taken into account within the UBC:

$$
\begin{aligned}
& S . F=\frac{\left(\sum_{i=1}^{i=N} Q_{u k, i}\right)}{F_{\text {load }}}, \\
& \left\{\begin{array}{lll}
\text { S.F } \geq 2, & \text { if } L_{i} \geq L_{0, i}, & \text { set } L_{i}=L_{0, i}, \\
\text { S.F }=1, & \text { if } L_{i} \leq L_{0, i}, & \text { set } L_{i}=L_{0, i},
\end{array}\right.
\end{aligned}
$$

where $Q_{u k, i}$ is the $\mathrm{UBC}$ of single pile $i$ in the initial design, $F_{\text {load }}$ is the total load on top of the raft, $L_{i}$ is the length of pile $i$, and $L_{0 i}$ is the length of pile $i$ in the initial design. Due to the influence of PPI of long-short piles, light microwave vibration of the length of R-pile is unavoidable. The length of R-pile can be adjusted according to equation (10) to ensure that the R-pile is always in a stable and unchanged reference state.

Different pile lengths need to be merged and combined after optimization design in consideration of the feasibility and convenience of construction. The minimum value of any $L_{i}-L_{j}$ needs to be no less than $0.5 \mathrm{~m}$ for the reason of too small a difference of pile lengths (e.g., $L_{i}-L_{j}<0.5 \mathrm{~m}$ ) will affect the feasibility of construction and then affect the optimization result.

This paper only studies the optimization design of pile groups in the elastic stage, and then, it is necessary to ensure

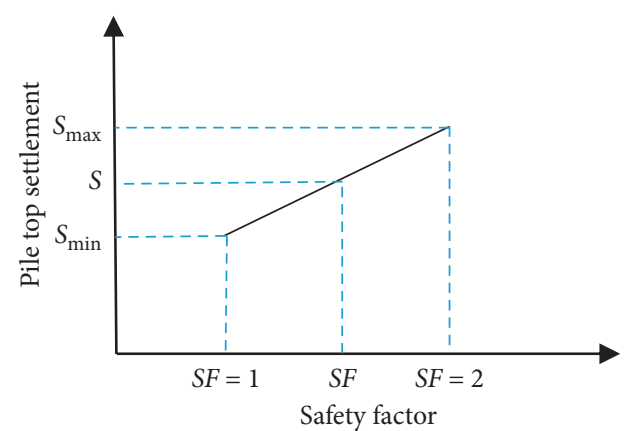

FIGURE 2: Linear correspondence between pile top settlement and safety factor.

that the load on top of each pile does not exceed its UBC during the optimization process. The load on top of each pile after optimization design should satisfy the following condition:

$$
P_{i} \leq Q_{u k, i}, \quad i=1,2,3, \ldots, N .
$$

If $P_{i}$ does not satisfy equation (11), the safety and affluence of the pile group are insufficient and the selected R-pile in this cycle is unreasonable and needs to be reselected. The largest $P_{i, \max }$ of the piles which does not satisfy equation (11) is selected as a new R-pile, and then, the previous cycle should be reoptimized according to $\mathrm{SF}=1$.

The flowchart of the PPI optimization method is shown in Figure 3.

\section{Illustrative Example}

3.1. Piled Raft Model (PRF) and Material. Two design cases are given in this paper to investigate the foregoing method. Both of the PRFs in the two cases consist of 121 concrete piles $(N=121)$ arranged in a $11 \times 11$ pattern and connected with a raft $(49 \mathrm{~m} \times 49 \mathrm{~m})$. The only difference is that the piles are $37 \mathrm{~m}$ long in Case 1 and $33 \mathrm{~m}$ long in Case 2. Pile diameters are all $1.5 \mathrm{~m}$ located with the same center-tocenter spacing of $4.5 \mathrm{~m}$. The calculation range of the soil in the horizontal direction is approximately 4 times the length of the raft. Generally, in order to reduce the influence of the boundary effect, the distance from the pile tip to the bottom of the model is 2 times the pile length $[34,35]$. In this study, the distance between the pile tip and the top of the bedrock is less than 2 times the pile length while the bedrock can be considered as a fixed end, so the bottom boundary of the model is located $5 \mathrm{~m}$ below the top of the bedrock. Table 1 and Figure 4 summarize the pile group parameters used in the analyses. For the calculation of load-settlement responses in piles, Moayedi and Rezaei [36] and Moayedi and Hayati [37] used neural network, and the software of ANSYS was used in this paper. In the ANSYS analyses, the nodes are shared along the pile-soil, pile-raft, and soil-raft interfaces, and zero slippage at these interfaces is assumed. The maximum element sizes in the horizontal direction and the vertical direction are $6 \mathrm{~m}$ and $3 \mathrm{~m}$, respectively. This results in about 530000 nodes and 840000 elements. 


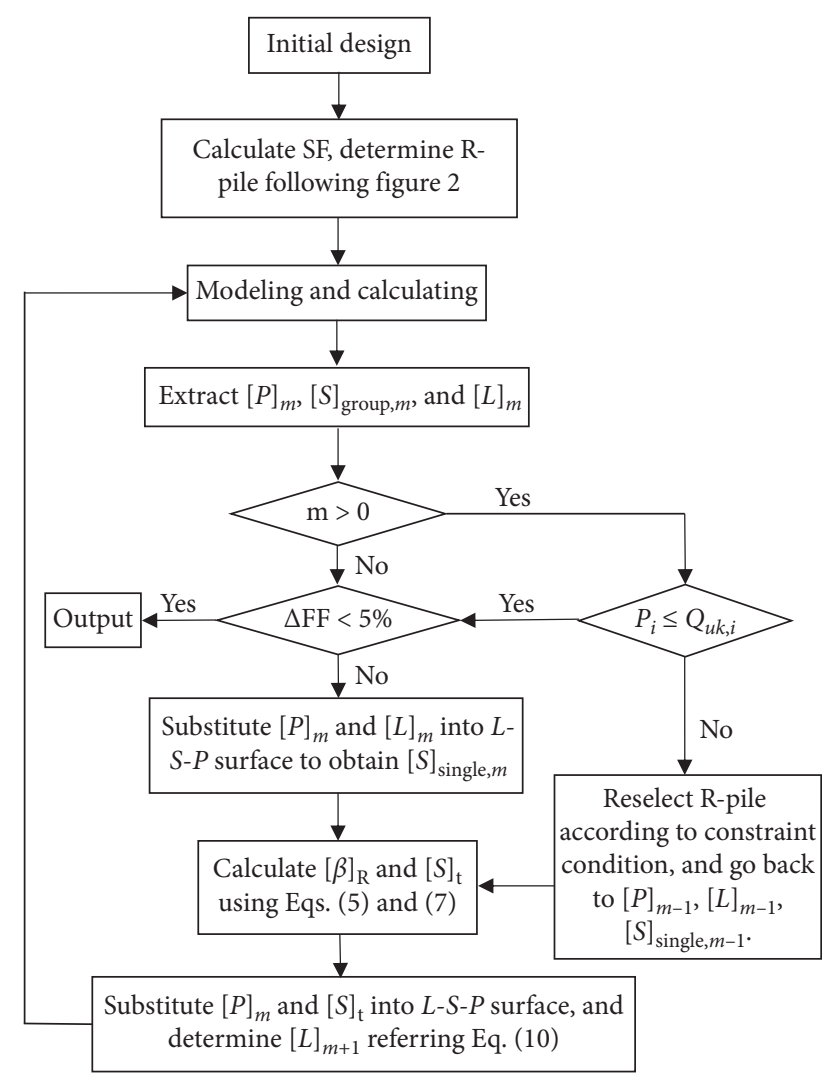

FIgURE 3: Flowchart of the PPI optimization method.

The soil model is assumed as an incremental nonlinear (hyperbolic) stress-dependent model (DC model), which is based on Hooke's law, and the main feature of which is a nonlinear relationship between stress and strain. Before the calculation, the initial Young modulus of each soil layer is calculated using the initial principal stresses $\left(\sigma_{1}\right.$ and $\left.\sigma_{3}\right)$, where the principal initial stresses of each element are obtained from equation (12). $K_{0}$ is the static lateral pressure coefficient, $z$ is the depth of the soil element center to the ground, and $\gamma$ is the gravity per unit volume of the soil:

$$
\begin{aligned}
& \left\{\begin{array}{l}
\sigma_{1}=\gamma z, \\
\sigma_{3}=K_{0} \gamma z,
\end{array}\right. \\
& K_{0}=0.95-\sin \varphi \text {. }
\end{aligned}
$$

A detailed description about the DC model can be found in Duncan and Chang [18] and Chen et al. [38]. The corresponding $8 \mathrm{DC}$ model parameters $\left(K, n, \varphi, c, R_{f} G, F\right.$, and $D)$ of the soil adopted in this paper are listed in Table 2 [39]. This paper assumes that the soil with the same property but different thickness has the same DC model parameters.

3.2. Boundary Conditions. All soil nodes at the bottom of the model (with a $Z$ coordinate of $-26 \mathrm{~m}$ ) are considered to be constrained in three directions, i.e., the displacements of the nodes in $X, Y$, and $Z$ directions are equal to zero. The outboard lateral boundary nodes only have displacement in $Z$ direction, and the motions in $X$ and $Y$ directions are constrained.
TABLE 1: The parameters of the pile, raft, and bedrock.

\begin{tabular}{lccc}
\hline Property & Elastic modulus $(\mathrm{Pa})$ & Poisson's ratio & Density $\left(\mathrm{kg} / \mathrm{m}^{3}\right)$ \\
\hline Raft & $2 \times 10^{10}$ & 0.2 & $2.4 \times 10^{3}$ \\
Pile & $3 \times 10^{10}$ & 0.2 & $2.4 \times 10^{3}$ \\
Bedrock & $1.5 \times 10^{10}$ & 0.3 & $2.45 \times 10^{3}$ \\
\hline
\end{tabular}

3.3. Loading and Analysis Procedure. In order to investigate the universality of the PPI method, two kinds of loads are used in this paper: uniform load and nonuniform load. The distribution of the two loads is shown in Figure 5. The total load $\left(F_{\text {load }}\right)$ on top of the raft is $900 \mathrm{MN}$ in Case 1 and is $1100 \mathrm{MN}$ in Case 2. There are 21 load steps during the analysis procedure. The first step $(i=1)$ is the gravity of the PRF system, and the external load on top of the raft is divided into 20 steps (step $i$ from 2 to 21 ) in order to consider the nonlinear characteristics of soil.

\section{Optimization Design via PPI Optimization Method}

As mentioned above, the $L-S-P$ surface of single piles is an important point during the whole optimization procedure. Therefore, the simulation of a single pile load test via FEM is needed to verify the validity of the analysis method.

4.1. Verification. A single pile load test (test pile) from Jiang [39] is simulated in this paper. The pile in the single pile model has a circular cross section with a diameter of $2.8 \mathrm{~m}$ and a depth of $125 \mathrm{~m}$ (the pile length between $+4 \mathrm{~m}$ and $-46 \mathrm{~m}$ is not in the soil). The soil model, which is composed of 9 soil layers, has a diameter of $100 \mathrm{~m}$ and a depth of $174 \mathrm{~m}$. The minimum and the maximum sizes of the model are $1 \mathrm{~m}$ and $5 \mathrm{~m}$, respectively. This results in about 19000 elements and 22000 nodes. The nodes along the pile-soil interfaces are shared, assuming that there is no slippage at these interfaces. Only a quarter of the actual model was modeled due to its symmetry. The other boundary conditions are the same as the PRF model. The load applied on top of the pile, which is $5 \mathrm{MPa}$, is divided into 20 steps, increasing from $0 \mathrm{MPa}$ to $5 \mathrm{MPa}$ with an increment load equal to $0.25 \mathrm{MPa}$.

The concrete pile has Young's modulus of $E=3.3 \times 10^{10} \mathrm{~Pa}$, an effective unit weight of $\gamma=1.4 \mathrm{MN} / \mathrm{m}^{3}$, and Poisson's ratio of $\nu=0.12$. The elastic constitutive model is used to model the concrete pile in this paper. The behavior of soil layers is modeled using the DC model. The corresponding soil parameters of the single pile test are shown in Table 3.

In Figure 6, the settlement results of the single pile load test are compared with those of the analytical prediction. The results indicate that the simulation results are in good agreement with experimental results, and the settlement error is only $3 \%$ under the same ultimate load, as shown in Table 4. That means the FEM adopted in this paper can simulate the stress state of the pile before its UBC. Before the load reaches the ultimate load, a sharp subsidence of the pile will not appear; i.e., the slippage of the interface between pile and soil is not severe. Therefore, unless the load on top of the 


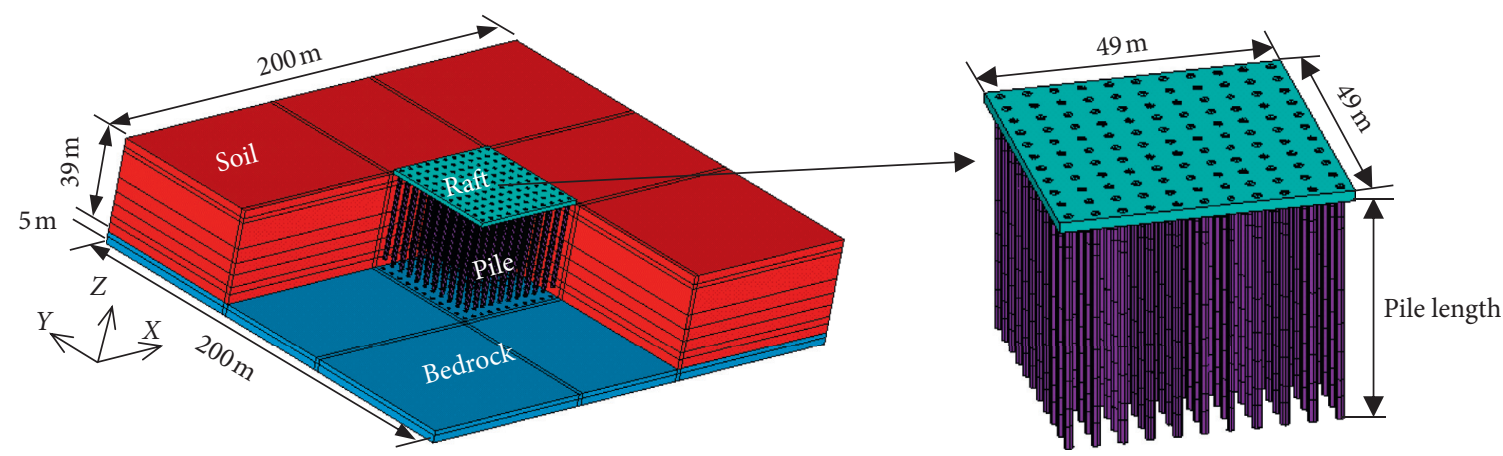

(a)

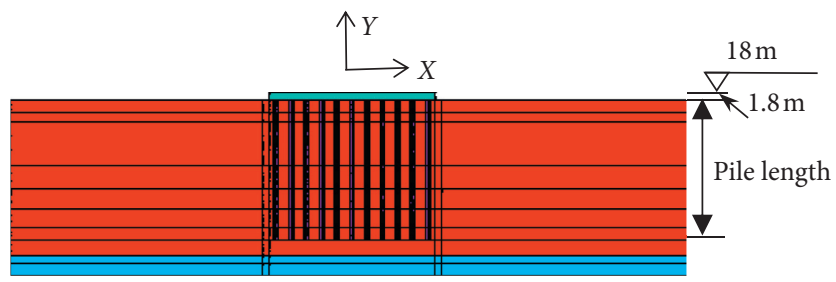

(b)

Figure 4: 3D view of the PRF: (a) the peripheral dimensions and components of the model; (b) cross-sectional view of (a).

TABLE 2: Soil parameters of the PRF used in the DC model.

\begin{tabular}{lccccccccccc}
\hline Soil type & High level $(\mathrm{m})$ & $R_{\mathrm{f}}$ & $K$ & $n$ & $G$ & $F$ & $D$ & $k_{u r}$ & $\varphi\left({ }^{\circ}\right)$ & $C(\mathrm{kPa})$ & $\rho_{s}\left(\mathrm{~g} / \mathrm{cm}^{3}\right)$ \\
\hline Fine sand & $15.5 \sim 18.4$ & 0.8 & 672 & 0.6 & 0.4 & 0 & 0 & 1009 & 38 & 16 & 1.1 \\
Medium-coarse gravel & $13.5 \sim 15.5$ & 0.8 & 519 & 0.55 & 0.4 & 0 & 0 & 781 & 35 & 12 & 1.2 \\
Medium-coarse sand & $1.9 \sim 13.5$ & 0.7 & 462 & 0.5 & 0.4 & 0 & 0 & 701 & 35 & 11 \\
Medium-coarse gravel & $-3.9 \sim 1.9$ & 0.8 & 502 & 0.6 & 0.4 & 0 & 0 & 762 & 38 & 16 & 1.1 \\
Fine sand & $-16.9 \sim-3.9$ & 0.9 & 431 & 0.6 & 0.4 & 0 & 0 & 663 & 35 & 16 & 1.2 \\
Medium-coarse gravel & $-21 \sim-16.9$ & 0.8 & 568 & 0.6 & 0.4 & 0 & 0 & 901 & 34 & 20 \\
\hline
\end{tabular}

pile exceeds its UBC, the assumption of rigid contact between pile and soil is valid.

4.2. Getting L-S-P Surface. The single pile load-settlement with different pile lengths in the soil layers of PRF can be simulated via the same simulation method in Section 4.1, and the corresponding load-settlement curves can be obtained (see Figure 7(a)). These different load-settlement curves of different piles length can be translated into $L-S-P$ surface via MATLAB software, as is shown in Figure 7(b).

The UBCs of the piles in different lengths need to be calculated by other methods because the simulation method can only simulate the state of pile top load before reaching the ultimate load. This paper uses empirical formulas (equation (13)) from the Chinese code [40] to estimate the UBC:

$$
Q_{u k}=u \sum \psi_{s i} q_{s i k} l_{i}+\psi_{p} q_{p k} A_{p}
$$

where $Q_{u k}$ is the UBC of a single pile; $u$ is the pile perimeter; $A_{p}$ is the section area at the tip of the pile; $l_{i}$ is the $i_{\text {th }}$ soil layer's thickness; $q_{s i k}$ and $q_{p k}$ are the ultimate shaft and tip resistance of $i_{\text {th }}$ soil layer, respectively; and $\psi_{s i}$ and $\psi_{p}$ are the effect coefficients of the shaft and tip resistance for piles in large diameter (diameter greater than $0.8 \mathrm{~m}$ ), respectively. The corresponding empirical parameters used in equation (13) of different soil are shown in Table 5.

The empirical value of UBC of the test pile is $43.6 \mathrm{MN}$, with only $3 \%$ error compared with the field test value $(45 \mathrm{MN})$. This indicates that the empirical parameters of the soil layers can be used to estimate the UBC of the other piles which have different pile lengths but in the same soil types (the thickness of the soil layer can be different). The empirical values of UBCs of the piles in different lengths in Figure 7 (a) are shown in Figure 8 . The turning point of the straight line in Figure 8 is caused by soil stratification.

4.3. Optimization Design of the Cases. The UBC of a single pile in $37 \mathrm{~m}$ long is $17.2 \mathrm{MN}$, which can be determined by equation (13) or Figure 8 . The safety factor SF of the PRF in Case 1 is more than that in Case 2 (SF is 2.3 under uniform load and 2.2 under nonuniform load). Therefore, the pile with the maximum settlement in the initial design is selected as R-pile (the pile in the circle), as is shown in Figure 9. Finally, the optimization process of Case 1 converges after 4 iterations under uniform load and 3 iterations under nonuniform load. The final pile lengths and the corresponding arrangements are shown in Table 6 and Figure 9. 


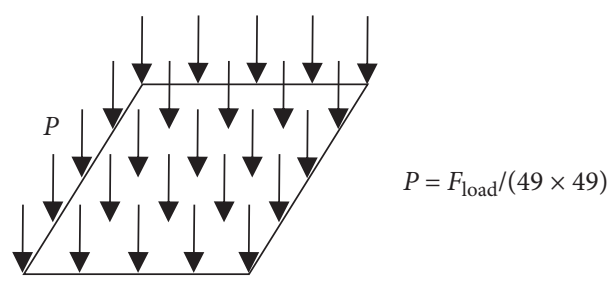

(a)

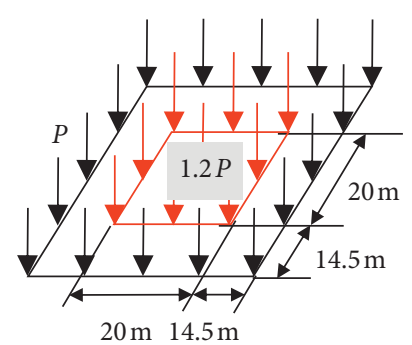

(b)

Figure 5: The load on top of the raft. (a) Uniform load. (b) Nonuniform load.

TABLE 3: Soil parameters of the single pile load test used in this paper (Jiang [39]).

\begin{tabular}{lccccccccccc}
\hline Type & High level $(\mathrm{m})$ & $R_{f}$ & $K$ & $n$ & $G$ & $F$ & $D$ & $k_{u r}$ & $\varphi\left({ }^{\circ}\right)$ & $C(\mathrm{kPa})$ & $\rho_{s}\left(\mathrm{~g} / \mathrm{cm}^{3}\right)$ \\
\hline Fine sand & $-65 \sim-46$ & 0.8 & 642 & 0.6 & 0.4 & 0 & 0 & 972 & 37 & 15 & 1.1 \\
Fine sand & $-74 \sim-65$ & 0.8 & 672 & 0.6 & 0.4 & 0 & 0 & 1009 & 38 & 16 & 1.1 \\
Medium-coarse gravel & $-86 \sim-74$ & 0.8 & 519 & 0.55 & 0.4 & 0 & 0 & 781 & 35 & 12 \\
Medium-coarse sand & $-95 \sim-86$ & 0.7 & 462 & 0.5 & 0.4 & 0 & 0 & 701 & 35 & 11 & 1.2 \\
Medium-coarse gravel & $-105 \sim-95$ & 0.8 & 502 & 0.6 & 0.4 & 0 & 0 & 762 & 38 & 16 \\
Fine sand & $-123 \sim-105$ & 0.9 & 431 & 0.6 & 0.4 & 0 & 0 & 663 & 35 & 16 \\
Medium-coarse gravel & $-138 \sim-123$ & 0.8 & 568 & 0.6 & 0.4 & 0 & 0 & 901 & 34 & 20 & 1.2 \\
Clay & $-166 \sim-138$ & 0.8 & 370 & 0.5 & 0.4 & 0 & 0 & 500 & 29 & 73 & 1.1 \\
Silty fine sand & $-220 \sim-166$ & 0.8 & 450 & 0.6 & 0.4 & 0 & 0 & 700 & 32 & 42 & 1.0 \\
\hline
\end{tabular}

The pile length varies from $33.5 \mathrm{~m}$ to $37 \mathrm{~m}$ under the uniform load and from $31.5 \mathrm{~m}$ to $37 \mathrm{~m}$ under nonuniform load. The purpose of this paper is to reduce the differential settlement, and the total volume of material will change according to the optimization results under different SF, rather than remain constant.

For Case 2, the UBC of a single pile in $33 \mathrm{~m}$ long is 14.1 MN. The safety factor SF is 1.55 under uniform load and 1.5 under nonuniform load. $1<\mathrm{SF}<2$, therefore, the pile with settlement close to $0.118 \mathrm{~m}$ is selected as R-pile under uniform load and the pile with settlement close to $0.121 \mathrm{~m}$ is selected as R-pile under nonuniform load, as is shown in Figure 10 (R-pile is the pile in the circle). The optimization process converges after 2 iterations under both uniform load and nonuniform load. The pile length and the corresponding arrangements are shown in Table 7 and Figure 10. The pile length changes from $28 \mathrm{~m}$ to $35 \mathrm{~m}$ under uniform load and from $27 \mathrm{~m}$ to $35 \mathrm{~m}$ under nonuniform load.

\section{Results and Discussion}

Differential settlements can result in an additional bending moment of the raft and then increase the cost of the raft. Therefore, the settlement of the raft is chosen as the main analysis objective in this paper to investigate the effectiveness of the optimization method.

\subsection{Result of Case 1}

5.1.1. Settlement of the Raft. The settlements on top of the raft in Case 1 under different loads before and after optimization design are compared in Figures 11 and 12. The

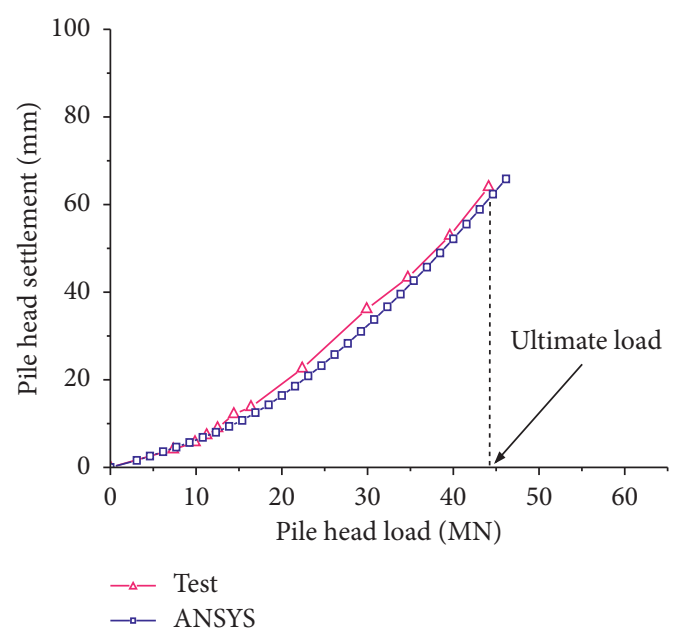

Figure 6: Load-settlement curves of a single pile.

TABle 4: Comparison of the pile top settlements at the ultimate load.

\begin{tabular}{lcc}
\hline Name & Field test value & FEM \\
\hline Ultimate load $(\mathrm{MN})$ & 45 & 45 \\
Settlement $(\mathrm{mm})$ & 64.67 & 64.84 \\
\hline
\end{tabular}

result shows that the settlement surface of the raft becomes more uniform after optimization design compared with the initial design, and the maximum settlement of the raft is moved out from the center of the raft.

Differential settlement is defined as the difference between the maximum and minimum settlement in this paper. 


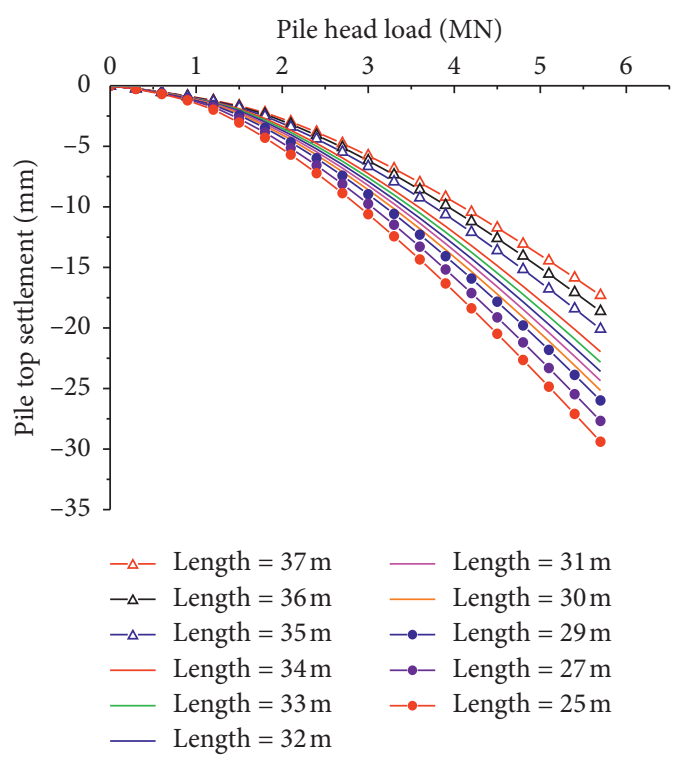

(a)

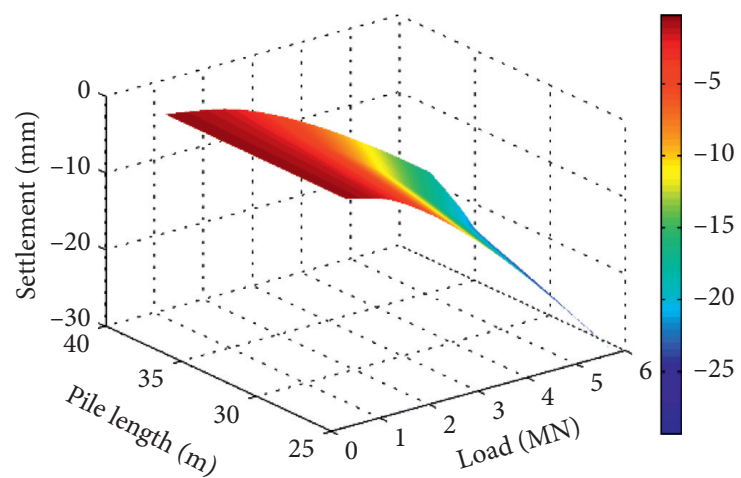

(b)

Figure 7: The relationship of load, pile length, and the pile top settlement: (a) load-settlement curves of single piles in different lengths; (b) $L$-S-P surface.

TABLE 5: Empirical parameters of the soil used in equation (13).

\begin{tabular}{|c|c|c|c|c|c|c|c|}
\hline \multirow{2}{*}{ Soil layer $i$} & \multirow{2}{*}{ Soil types } & \multirow{2}{*}{$q_{s i k}(\mathrm{kPa})$} & \multirow{2}{*}{$q_{p k}(\mathrm{MPa})$} & \multirow{2}{*}{$\psi_{s i}$} & \multirow{2}{*}{$\psi_{p}$} & \multicolumn{2}{|c|}{$l_{i}(\mathrm{~m})$} \\
\hline & & & & & & Test pile & Simulated piles \\
\hline 1 & Fine sand & 70 & - & $(0.8 / 1.5)^{1 / 3}$ & $(0.8 / 1.5)^{1 / 3}$ & 9 & 3 \\
\hline 2 & Medium-coarse gravel & 110 & - & $(0.8 / 1.5)^{1 / 3}$ & $(0.8 / 1.5)^{1 / 3}$ & 12 & 2 \\
\hline 3 & Medium-coarse sand & 100 & 2.1 & $(0.8 / 1.5)^{1 / 3}$ & $(0.8 / 1.5)^{1 / 3}$ & 9 & 11 \\
\hline 4 & Medium-coarse gravel & 120 & 2.2 & $(0.8 / 1.5)^{1 / 3}$ & $(0.8 / 1.5)^{1 / 3}$ & 10 & 6 \\
\hline 5 & Fine sand & 80 & 1.5 & $(0.8 / 1.5)^{1 / 3}$ & $(0.8 / 1.5)^{1 / 3}$ & 16 & 13 \\
\hline 6 & Medium-coarse gravel & 120 & 2.6 & $(0.8 / 1.5)^{1 / 3}$ & $(0.8 / 1.5)^{1 / 3}$ & - & 2 \\
\hline
\end{tabular}

Note. The tip resistances $\left(q_{p k}\right)$ of the soil take the lower limit of the given range in the Chinese code [35].

Table 8 gives a detailed comparison of the differential settlement of the raft (DS raft) under different conditions. The DS raft of Case 1 is reduced by $80 \%$ from $0.015 \mathrm{~m}$ to $0.003 \mathrm{~m}$ under uniform load and by $87 \%$ from $0.02 \mathrm{~m}$ to $0.0025 \mathrm{~m}$ under nonuniform load.

5.1.2. Verification of UBC of Piles in Different Lengths. The comparison of the maximum pile top loads of different pile lengths in different models and their corresponding UBCs is shown in Tables 9 and 10. The result indicates that no pile exceeds the corresponding UBC during the optimization procedure, which can also be verified in Figure 8.

\subsection{Result of Case 2}

5.2.1. Settlement of the Raft. Figures 13 and 14 give the comparison of the settlement on top of the raft in Case 2 under different loads before and after optimization design. The result is similar to that in Case 1, where the settlement surface of the raft is more uniform by using different pile lengths compared with the initial design, and the maximum

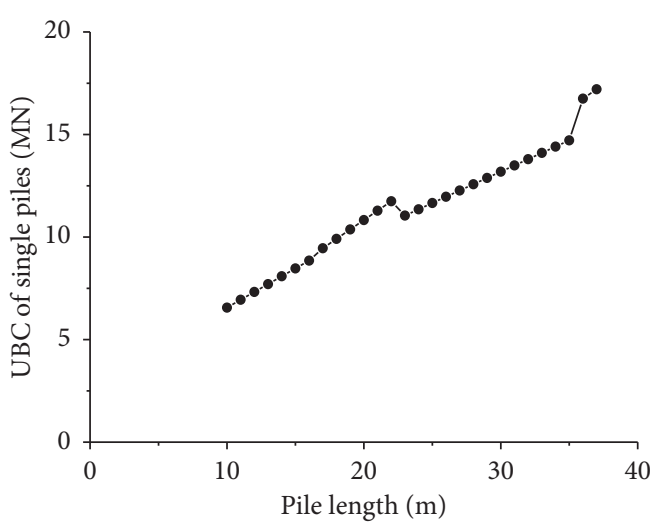

Figure 8: The relationship of the UBC of single piles and corresponding pile length.

settlement of the raft is moved out from the center of the raft. A detailed comparison of the DS rafts in Case 2 under different loads is shown in Table 11. The DS raft is reduced from $0.047 \mathrm{~m}$ to $0.01 \mathrm{~m}$ under uniform load, by $79 \%$, and from $0.051 \mathrm{~m}$ to $0.0076 \mathrm{~m}$ under nonuniform load, by $85 \%$. 


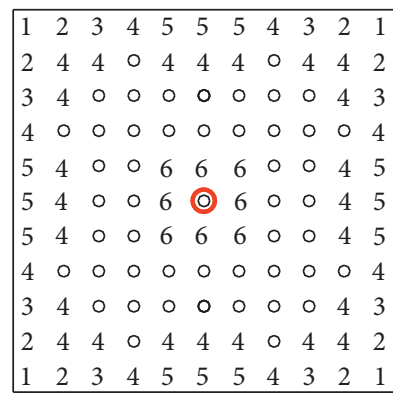

(a)

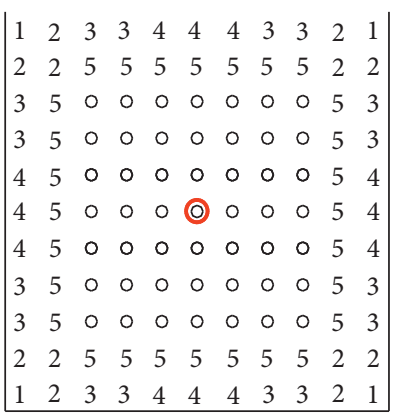

(b)

Figure 9: Pile length arrangement across the raft after optimization design under different surface loads (Case 1). (a) Optimization design under uniform load $(\mathrm{O}-\mathrm{U})$. (b) Optimization design under nonuniform load $(\mathrm{O}-\mathrm{N})$.

TABLE 6: Pile length corresponding to different pile numbers in Figure 9 (Case 1).

\begin{tabular}{lccccccc}
\hline Pile-Case 1 & 1 & 2 & 3 & 4 & 5 & 6 & Others \\
\hline Pile length $(\mathrm{O}-\mathrm{U})$ & $33.5 \mathrm{~m}$ & $34 \mathrm{~m}$ & $35 \mathrm{~m}$ & $35.5 \mathrm{~m}$ & $36 \mathrm{~m}$ & $36.5 \mathrm{~m}$ & $37 \mathrm{~m}$ \\
Pile length $(\mathrm{O}-\mathrm{N})$ & $31.5 \mathrm{~m}$ & $34 \mathrm{~m}$ & $35 \mathrm{~m}$ & $34.5 \mathrm{~m}$ & $36 \mathrm{~m}$ & - & $37 \mathrm{~m}$ \\
\hline
\end{tabular}

$\left.\begin{array}{lllllllllll}1 & 2 & 3 & 4 & 0 & 0 & 0 & 4 & 3 & 2 & 1 \\ 2 & 4 & 0 & 0 & 5 & 5 & 5 & 0 & 0 & 4 & 2 \\ 3 & 0 & 0 & 5 & 5 & 5 & 5 & 5 & 0 & 0 & 3 \\ 4 & 0 & 5 & 5 & 6 & 6 & 6 & 5 & 5 & 0 & 4 \\ 0 & 5 & 5 & 6 & 6 & 6 & 6 & 6 & 5 & 5 & 0 \\ 0 & 5 & 5 & 6 & 6 & 7 & 6 & 6 & 5 & 5 & 0 \\ 0 & 5 & 5 & 6 & 6 & 6 & 6 & 6 & 5 & 5 & 0 \\ 4 & 0 & 5 & 5 & 6 & 6 & 6 & 5 & 5 & 0 & 4 \\ 3 & 0 & 0 & 5 & 5 & 5 & 5 & 5 & 0 & 0 & 3 \\ 2 & 4 & 0 & 0 & 5 & 5 & 5 & 0 & 0 & 4 & 2 \\ 1 & 2 & 3 & 4 & 0 & 0 & 0 & 4 & 3 & 2 & 1\end{array}\right] \quad\left[\begin{array}{lllllllllll|}1 & 2 & 3 & 4 & 5 & 5 & 5 & 4 & 3 & 2 & 1 \\ 2 & 4 & 0 & 0 & 6 & 6 & 6 & 0 & 0 & 4 & 2 \\ 3 & 0 & 0 & 6 & 7 & 7 & 7 & 6 & 0 & 0 & 3 \\ 4 & 0 & 6 & 7 & 8 & 8 & 8 & 7 & 6 & 0 & 4 \\ 5 & 6 & 7 & 8 & 8 & 8 & 8 & 8 & 7 & 6 & 5 \\ 5 & 6 & 7 & 8 & 8 & 8 & 8 & 8 & 7 & 6 & 5 \\ 5 & 6 & 7 & 8 & 8 & 8 & 8 & 8 & 7 & 6 & 5 \\ 4 & 0 & 6 & 7 & 8 & 8 & 8 & 7 & 6 & 0 & 4 \\ 3 & 0 & 0 & 6 & 7 & 7 & 7 & 6 & 0 & 0 & 3 \\ 2 & 4 & 0 & 0 & 6 & 6 & 6 & 0 & 0 & 4 & 2 \\ 1 & 2 & 3 & 4 & 5 & 5 & 5 & 4 & 3 & 2 & 1 \\ \hline\end{array}\right.$

(a)

(b)

Figure 10: Pile length arrangement across the raft after optimization design under different surface loads (Case 2). (a) Optimization design under uniform load $(\mathrm{O}-\mathrm{U})$. (b) Optimization design under nonuniform load $(\mathrm{O}-\mathrm{N})$.

TABLe 7: Pile length corresponding to different pile numbers in Figure 10 (Case 2).

\begin{tabular}{|c|c|c|c|c|c|c|c|c|c|}
\hline Pile-Case 2 & 1 & 2 & 3 & 4 & 5 & 6 & 7 & 8 & Others \\
\hline Pile length $(\mathrm{O}-\mathrm{U})$ & $28 \mathrm{~m}$ & $30 \mathrm{~m}$ & $31 \mathrm{~m}$ & $32 \mathrm{~m}$ & $34 \mathrm{~m}$ & $34.5 \mathrm{~m}$ & $35 \mathrm{~m}$ & - & $33 \mathrm{~m}$ \\
\hline Pile length $(\mathrm{O}-\mathrm{N})$ & $27 \mathrm{~m}$ & $29 \mathrm{~m}$ & $31 \mathrm{~m}$ & $32 \mathrm{~m}$ & $32.5 \mathrm{~m}$ & $34 \mathrm{~m}$ & $34.5 \mathrm{~m}$ & $35 \mathrm{~m}$ & $33 \mathrm{~m}$ \\
\hline
\end{tabular}

5.2.2. Verification of Ultimate Bearing Capacity of Piles in Different Lengths. The maximum pile top loads of different pile lengths are compared with their UBCs in Tables 12 and 13. The result indicates that no pile exceeds the corresponding UBC during the optimization procedure.

5.3. Discussion. Pile-soil interaction is the main reason leading to different pile lengths when the load is uniform, and the difference between different pile lengths is usually not too large. Therefore, the effect of the error due to the merging and combining of pile lengths is more prominent, and then, more iterations are needed to make up for it.
When the load is nonuniform, the difference of different pile lengths under nonuniform load is more obvious after optimization compared with that under uniform load. Even though some differences of the pile lengths are eliminated by merging and combining, the influence on the optimization result by this error is not as obvious as that under uniform load, and then fewer iterations are needed, which can be seen from Tables 8 and 11 .

The safety factor in Case 1 is more than 2, and it is between 1 and 2 in Case 2. Increasing and reducing pile lengths can be adopted at the same time in Case 2 during the optimization process as is suggested before, while Case 1 can only choose reducing the pile lengths. Therefore, the models 


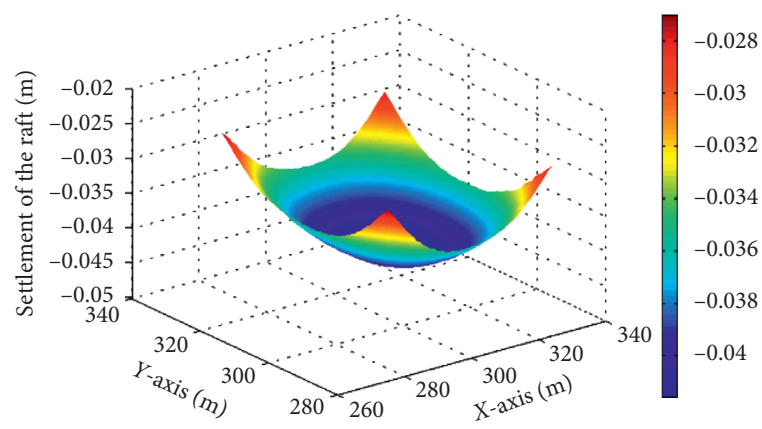

(a)

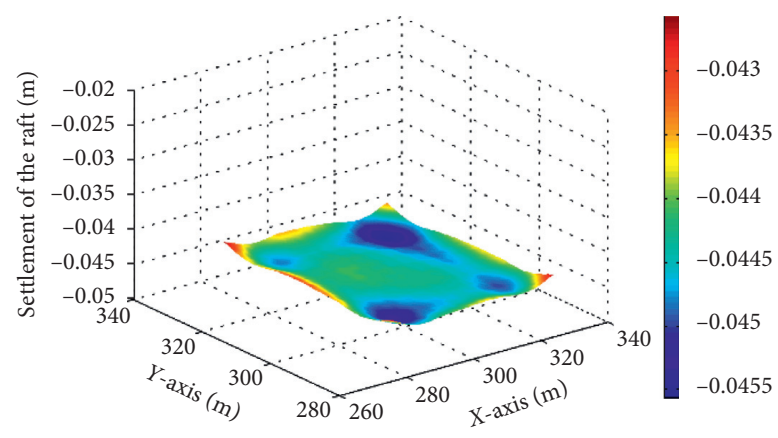

(c)

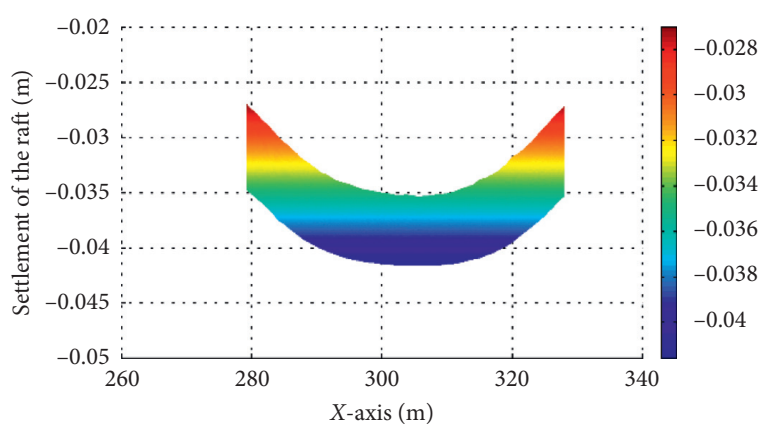

(b)

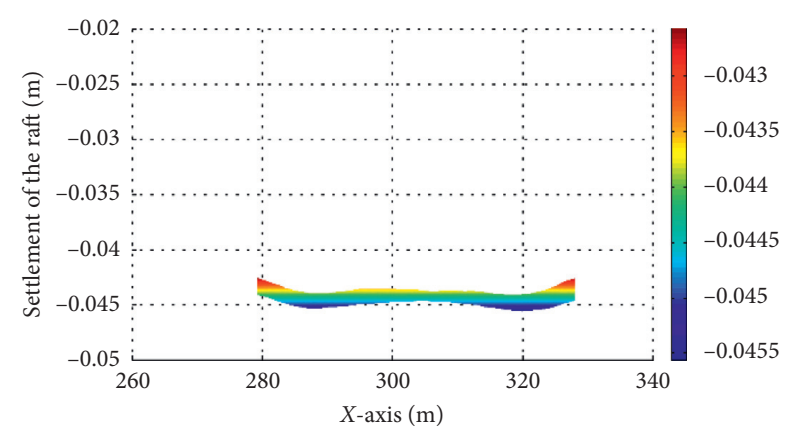

(d)

FIgURE 11: Comparison of the raft settlements under uniform load before and after optimization design (Case 1). (a) Initial design, 3D view. (b) Initial design, $X Z$ view. (c) Optimization design, 3D view. (d) Optimization design, $X Z$ view.

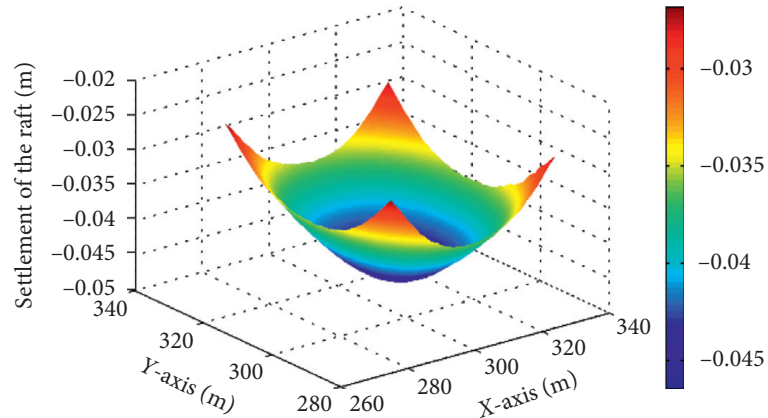

(a)

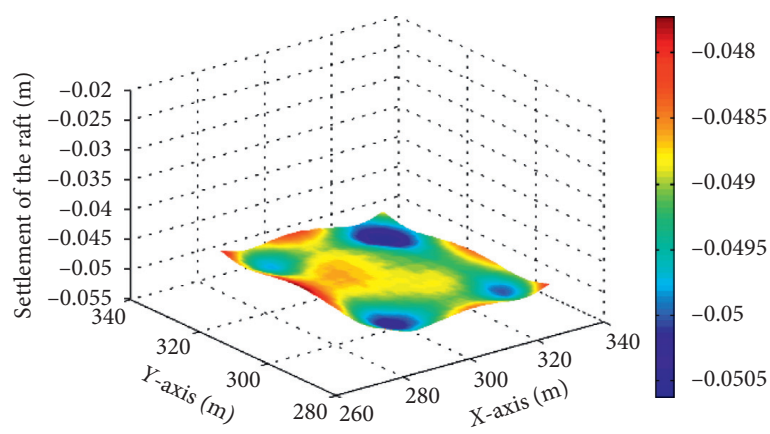

(c)

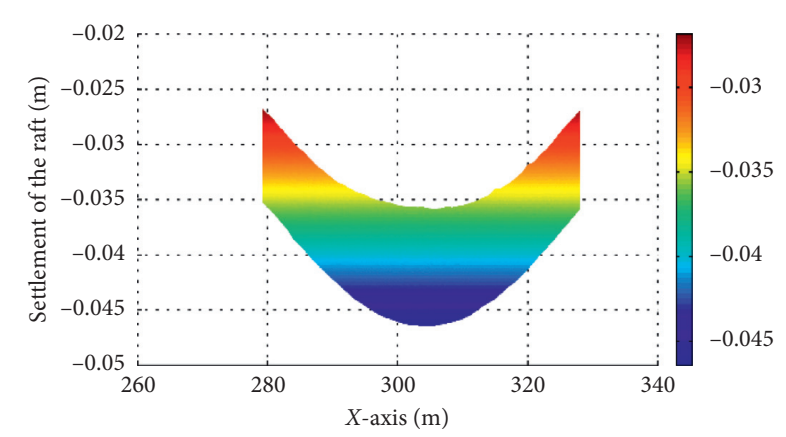

(b)

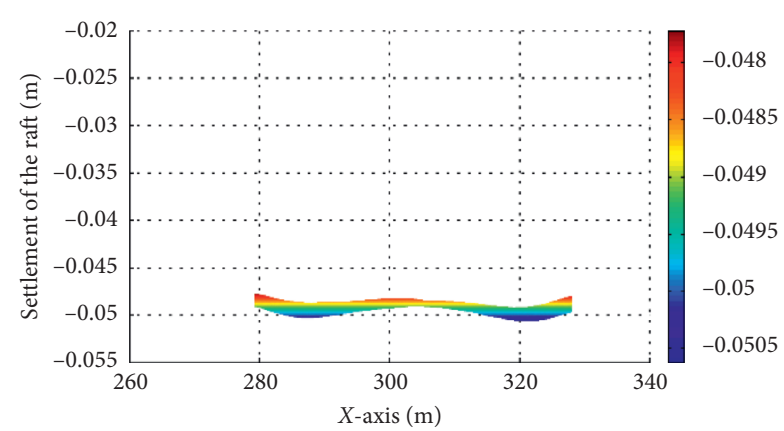

(d)

Figure 12: Comparison of the raft settlements under nonuniform load before and after optimization design (Case 1). (a) Initial design, 3D view. (b) Initial design, $X Z$ view. (c) Optimization design, 3D view. (d) Optimization design, $X Z$ view. 
TABLE 8: Comparison of the DS rafts (Case 1, SF >2).

\begin{tabular}{lcccc}
\hline Case & I-U & O-U & I-N & O-N \\
\hline DS raft & 0.015 & 0.003 & 0.02 & 0.0029 \\
FF & - & $80 \%$ & - & $86 \%$ \\
\hline
\end{tabular}

Note. $\mathrm{I}-\mathrm{U}=$ initial design under uniform load; $\mathrm{I}-\mathrm{N}=$ initial design under nonuniform load.

TABLE 9: The maximum pile top loads and the corresponding UBCs of different pile lengths under uniform load (MN) (Case 1).

\begin{tabular}{lccccccc}
\hline$P_{\max }$ & 1 & 2 & 3 & 4 & 5 & 6 & $37 \mathrm{~m}$ \\
\hline Initial design (SF $>2)$ & - & - & - & - & - & 5.7 \\
O-U & 4.5 & 4.1 & 4.6 & 4.8 & 5.1 & 5.5 & 5.6 \\
UBC & 14.2 & 14.4 & 14.7 & 15.5 & 16.7 & 16.9 \\
\hline
\end{tabular}

Note. $P_{\max }=$ the maximum load on top of the piles with the same pile length.

TABle 10: The maximum pile top loads and the corresponding UBCs of different pile lengths under nonuniform load (MN) (Case 1).

\begin{tabular}{lccccccc}
\hline$P_{\max }$ & 1 & 2 & 3 & 4 & 5 & 6 & $37 \mathrm{~m}$ \\
\hline Initial design (SF $>2)$ & - & - & - & - & - & 6.4 \\
O-N & 4.3 & 4.3 & 4.8 & 5 & 5.3 & 5.8 & 6.5 \\
UBC & 13.6 & 14.4 & 14.7 & 15.5 & 16.7 & 16.9 \\
\hline
\end{tabular}

Note. $P_{\max }=$ the maximum load on top of the piles with the same pile length.

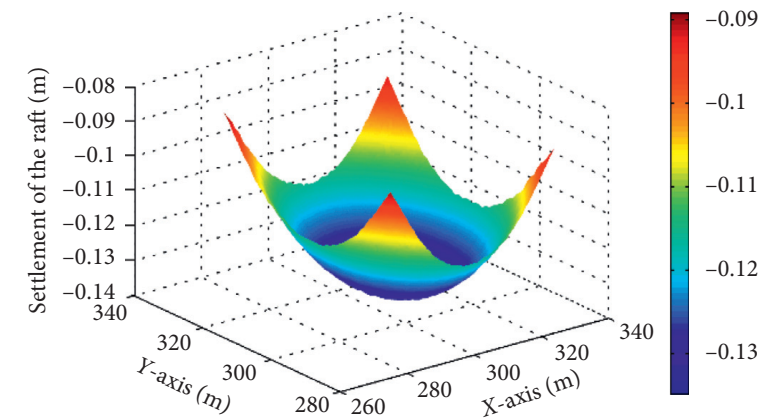

(a)

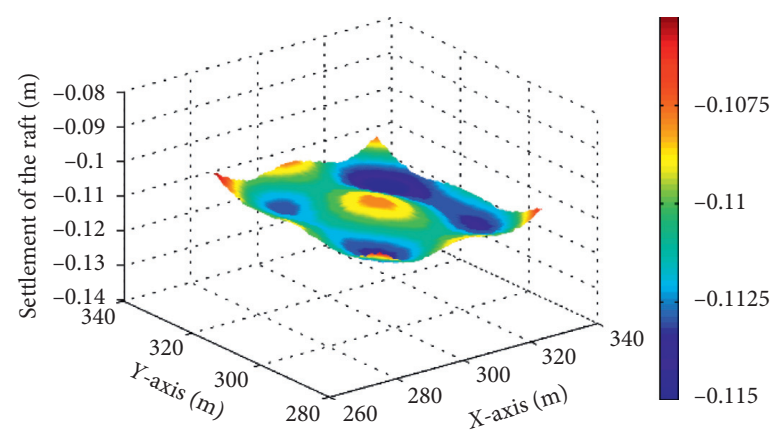

(c)

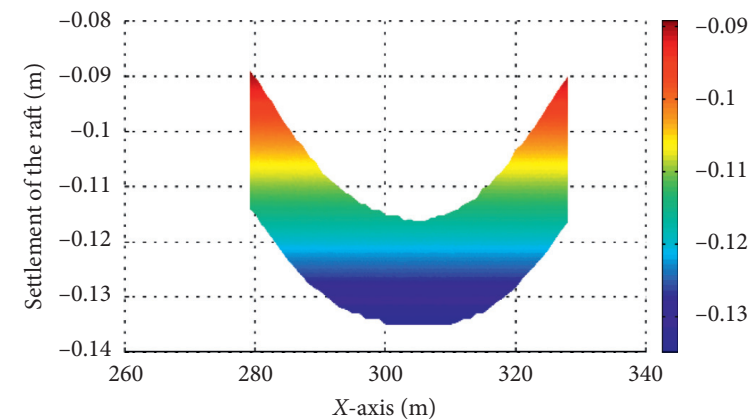

(b)

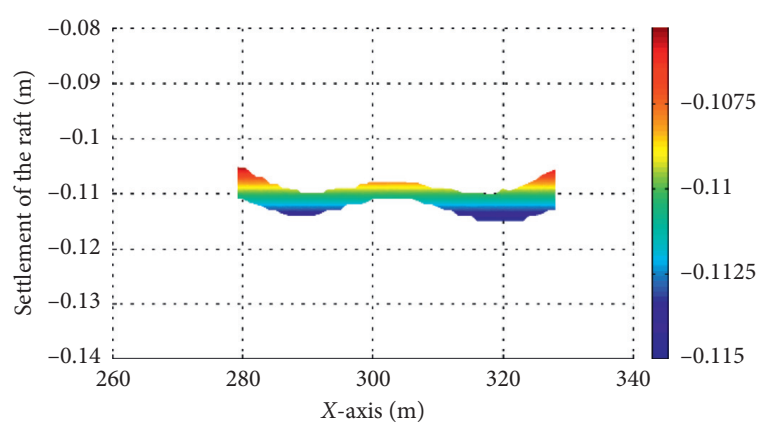

(d)

FIgURe 13: Comparison of the raft settlements under uniform load before and after optimization design (Case 2). (a) Initial design, 3D view. (b) Initial design, $X Z$ view. (c) Optimization design, 3D view. (d) Optimization design, $X Z$ view.

in Case 1 need more iterations compared with those in Case 2 (see Figure 9 and Table 6). The DS raft always shows a higher optimization efficiency under nonuniform load because of the merging and combing of pile lengths compared with that under uniform load.

Compared with the optimization method [41] proposed by the authors, the optimization method proposed in this paper is more effective: (1) the FF of differential settlement of piled raft foundation is significantly improved; (2) the realization of optimization method is more automatic, avoiding the error caused by manual participation; and (3) it is easier to change the pile length for construction compared with change pile diameter and pile spacing. 


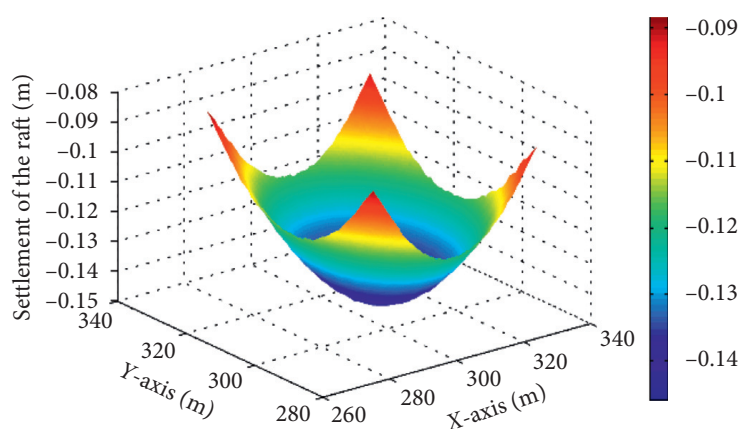

(a)

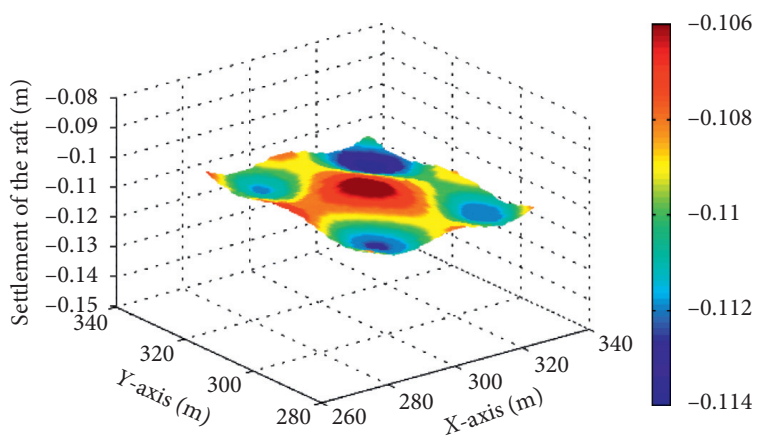

(c)

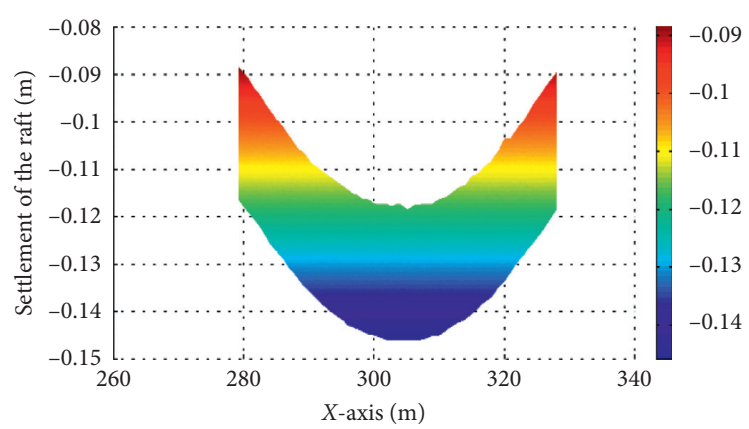

(b)

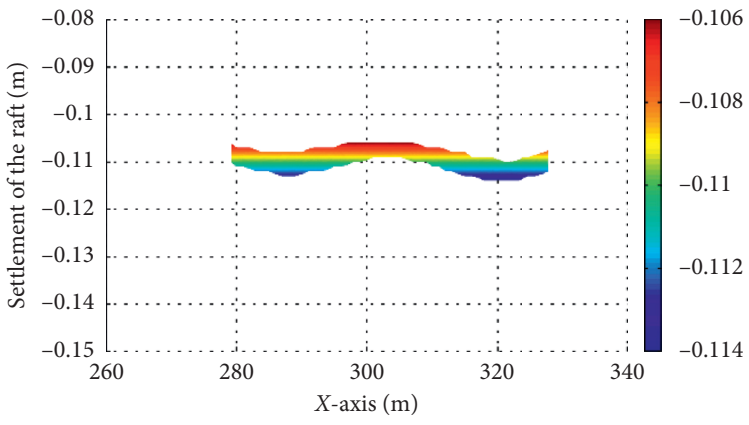

(d)

Figure 14: Comparison of the raft settlement under nonuniform load before and after optimization design (Case 2). (a) Initial design, 3D view. (b) Initial design, $X Z$ view. (c) Optimization design, 3D view. (d) Optimization design, $X Z$ view.

TABle 11: Comparison of the DS rafts (Case 2, $1<\mathrm{SF}<2$ ).

\begin{tabular}{lcccc}
\hline Case & $\mathrm{I}-\mathrm{U}$ & $\mathrm{O}-\mathrm{U}$ & $\mathrm{I}-\mathrm{N}$ & \\
\hline DS raft & 0.047 & 0.01 & 0.051 & 0.0076 \\
FF & - & $79 \%$ & - & $85 \%$ \\
\hline
\end{tabular}

Note. I-U = initial design under uniform load; I-N = initial design under nonuniform load.

TABLE 12: The maximum pile top loads and the corresponding UBCs of different pile lengths under uniform load (MN) (Case 2).

\begin{tabular}{lcccccccc}
\hline$P_{\max }$ & 1 & 2 & 3 & 4 & 5 & 6 & 7 & $33 \mathrm{~m}$ \\
\hline Initial design $(1<\mathrm{SF}<2)$ & - & - & - & - & - & - & - & 7.1 \\
$\mathrm{O}-\mathrm{U}$ & 6.1 & 5.5 & 5.8 & 6.2 & 7.1 & 7.6 & 7.7 & 6.7 \\
$\mathrm{UBC}$ & 12.6 & 13.2 & 13.5 & 13.8 & 14.4 & 14.6 & 14.7 & 14.1 \\
\hline
\end{tabular}

Note. $P_{\max }=$ the maximum load on top of the piles with the same pile length.

TABLE 13: The maximum pile top loads and the corresponding UBCs of different pile lengths under nonuniform load (MN) (Case 2).

\begin{tabular}{lccccccccc}
\hline$P_{\max }$ & 1 & 2 & 3 & 4 & 5 & 6 & 7 & 8 & $33 \mathrm{~m}$ \\
\hline Initial design $(1<\mathrm{SF}<2)$ & - & - & - & - & - & - & - & - & 6.4 \\
O-N & 5.9 & 5.2 & 5.8 & 6.2 & 6.3 & 7 & 7.6 & 8.2 & 6.2 \\
UBC & 12.3 & 12.9 & 13.5 & 13.8 & 14 & 14.4 & 14.6 & 14.7 & 14.1 \\
\hline
\end{tabular}

Note. $P_{\max }=$ the maximum load on top of the piles with the same pile length.

\section{Conclusions}

This paper proposes an optimization method based on PPI theory aiming to remove the differential settlement of the PRFs. ANSYS package software is used in conjunction with DC nonlinear elastic soil model to simulate PRFs under different surface loads to investigate the optimization efficiency of the PPI optimization method. After the verification of a single pile load test simulation, the settlement load curves of single piles with different lengths 
via the same simulation method are obtained to establish $L-S-P$ surface of single piles. The results emphasize the superior advantages (the optimization rate FF is nearly more than $80 \%$ without too many iterations) of the PPI optimization method over the initial design by the traditional method in reducing the differential settlements of PRFs. Based on the results, other conclusions are proposed:

(1) The problem of unknown pile top loads of pile groups in the application of conventional IFM is solved via FEM. The simplified method, which defined raft as rigid and flexible, is avoided.

(2) According to Poulos's formula [27] for calculating the settlement of a pile in pile group, which is based on the superposition method, the influence coefficient $\left(\beta_{i}\right)$ of other piles in pile group on pile $i$ is obtained. The relationship between the settlement of a pile in a single pile system and the settlement of the pile in a pile group system under the same pile top loads is established.

(3) The results before and after optimization show that the PPI optimization method has high optimization efficiency. The DS raft is reduced by nearly $80 \%$ under uniform load and more than $85 \%$ under nonuniform load, which results in higher optimization rate compared with published works $[5,41]$. It can be seen that the uneven distribution of the load does not affect the efficiency of the optimization method proposed in this paper.

(4) The traditional uniform pile layout design is selected as the initial design to facilitate comparison in this paper. However, the optimization method does not limit the load type and the initial design of the pile arrangement, as is shown in Figure 3. The reason is the optimization of each pile is independent in the optimization process. Therefore, this method has strong applicability, especially in the optimization design with the differential settlement of the pile foundation as the control objective.

The selection of the R-pile is a key point of this research method, which depends on the SF of the initial design of the pile group and determines the bearing capacity level of PRF after the optimized design. The SF is directly proportional to the economic investment of pile foundation; therefore, the proposed method does not directly incorporate economic optimization into the optimization objective, but gives different optimization suggestions for PRFs under different safety factors. In order to further study the optimization method in the near future, the centrifuge test or small-scale test will be studied to more accurately assess the performance of the model for pile groups and piled raft, and the parametric analysis will be studied to research the importance of parameters. Furthermore, with the continuous development of artificial intelligence or artificial neural network, future research efforts also can be focused on the combination of artificial intelligence and optimization design.

\section{Data Availability}

The data used to support the findings of this study are included within the article.

\section{Conflicts of Interest}

There are no conflicts of interest regarding the theoretical and numerical observations introduced in this paper.

\section{Acknowledgments}

This work was supported by the National Key Research and Development Project in China (grant no. 2016YFB0201001).

\section{Supplementary Materials}

The supplementary material is the database for the Figures 11-14 within the manuscript. (Supplementary Materials)

\section{References}

[1] A. T. Ghalesari, A. Barari, P. F. Amini, and L. B. Ibsen, "Development of optimum design from static response of pile-raft interaction," Journal of Marine Science and Technology, vol. 20, no. 2, pp. 331-343, 2015.

[2] H. G. Poulos, "Pile behaviour-theory and application," Géotechnique, vol. 39, no. 3, pp. 365-415, 1989.

[3] A. T. Ghalesari and H. Rasouli, "The effect of gravel layer on the behavior of piled raft foundations," in Proceedings of the Advances in Soil Dynamics and Foundation Engineering, pp. 373-382, ASCE, Shanghai, China, May 2014.

[4] F. Liang, L. Chen, and J. Han, "Integral equation method for analysis of piled rafts with dissimilar piles under vertical loading," Computers and Geotechnics, vol. 36, no. 3, pp. 419-426, 2009.

[5] Y. F. Leung, A. Klar, and K. Soga, "Theoretical study on pile length optimization of pile groups and piled rafts," Journal of Geotechnical and Geoenvironmental Engineering, vol. 136, no. 2, pp. 319-330, 2010.

[6] K. N. Kim, S.-H. Lee, K.-S. Kim, C.-K. Chung, M. M. Kim, and H. S. Lee, "Optimal pile arrangement for minimizing differential settlements in piled raft foundations," Computers and Geotechnics, vol. 28, no. 4, pp. 235-253, 2001.

[7] L. D. Sanctis, A. Mandolini, G. Russo, and C. Viggiani, "Some remarks on the optimum design of piled rafts," in Proceedings of the International Deep Foundations Congress, pp. 405-425, ASCE, Orlando, FL, USA, February 2002.

[8] Y. L. Li, J. F. Wang, Q. Wang, and K. Yang, "Optimization design study on variable stiffness of the pile raft foundation in high-rise building," Advanced Materials Research, vol. 243249, pp. 2498-2502, 2011.

[9] M. M. Sales, M. Prezzi, R. Salgado, Y. S. Choi, and J. Lee, "Load-settlement behaviour of model pile groups in sand under vertical load," Journal of Civil Engineering and Management, vol. 23, no. 8, pp. 1148-1163, 2017.

[10] S. Shrestha, N. Ravichandran, and P. Rahbari, "Geotechnical design and design optimization of a pile-raft foundation for tall onshore wind turbines in multilayered clay," International Journal of Geomechanics, vol. 18, no. 2, 2017.

[11] A. T. Ghalesari and A. J. Choobbasti, "Numerical analysis of settlement and bearing behaviour of piled raft in Babol clay," 
European Journal of Environmental \& Civil Engineering, vol. 22, no. 8, pp. 978-1003, 2016.

[12] C. J. Padfield and M. Sharrock, Settlement of Structures on Clay Soils, Construction Industry Research \& Information Institute, London, UK, 1983.

[13] D. D. C. Nguyen, D. S. Kim, and S. B. Jo, "Settlement of piled rafts with different pile arrangement schemes via centrifuge tests," Journal of Geotechnical and Geoenvironmental Engineering, vol. 139, no. 10, pp. 1690-1698, 2013.

[14] D. D. C. Nguyen, D.-S. Kim, and S.-B. Jo, "Parametric study for optimal design of large piled raft foundations on sand," Computers and Geotechnics, vol. 55, pp. 14-26, 2014.

[15] Y. F. Leung, A. Klar, K. Soga, and N. A. Hoult, "Superstructure-foundation interaction in multi-objective pile group optimization considering settlement response," Canadian Geotechnical Journal, vol. 54, no. 10, pp. 1408-1420, 2017.

[16] H. M. Algin, "Optimised design of jet-grouted rafts subjected to nonuniform vertical loading," KSCE Journal of Civil Engineering, vol. 4, pp. 1-15, 2017.

[17] T. Senjuntichai, N. Sornpakdee, J. Teerawong, and R. K. N. D. Rajapakse, "Time-dependent response of an axially loaded elastic bar in a multilayered poroelastic medium," Journal of Engineering Mechanics, vol. 133, no. 5, pp. 578-587, 2007.

[18] J. M. Duncan and C. Y. Chang, "Nonlinear analysis of stress and strain in soils," Journal of the Soil Mechanics and Foundations Division, vol. 96, no. 5, pp. 1629-1653, 1970.

[19] M. Modarresi, H. Rasouli, A. T. Ghalesari, and M. H. Baziar, "Experimental and numerical study of pile-to-pile interaction factor in sandy soil," Procedia Engineering, vol. 161, pp. 1030-1036, 2016.

[20] A. T. Ghalesari, A. Barari, P. F. Amini, and L. B. Ibsen, "The settlement behavior of piled raft interaction in undrained soil," in Proceedings of the IACGE 2013: Challenges and Recent Advances in Geotechnical and Seismic Research and Practices, pp. 605-612, ASCE, Chengdu, China, October 2013.

[21] S. C. Wong and H. G. Poulos, "Approximate pile-to-pile interaction factors between two dissimilar piles," Computers and Geotechnics, vol. 32, no. 8, pp. 613-618, 2005.

[22] Q. Zhang and Z. Zhang, "Study on interaction between dissimilar piles in layered soils," International Journal for Numerical and Analytical Methods in Geomechanics, vol. 35, no. 1, pp. 67-81, 2011.

[23] H. G. Poulos, "Analysis of the settlement of pile groups," Géotechnique, vol. 18, no. 4, pp. 449-471, 1968.

[24] H. G. Poulos, "Modified calculation of pile-group settlement interaction," Journal of Geotechnical Engineering, vol. 114, no. 6, pp. 697-706, 1988.

[25] B. A. McCabe and B. B. Sheil, "Pile group settlement estimation: suitability of nonlinear interaction factors," International Journal of Geomechanics, vol. 15, no. 3, 2015.

[26] B. B. Sheil, B. A. Mccabe, E. M. Comodromos, and B. M. Lehane, "Pile groups under axial loading: An appraisal of simplified nonlinear prediction models," Géotechnique, vol. 69, no. 7, pp. 565-579, 2019.

[27] H. G. Poulos, "Pile group settlement estimation-research to practice," in Proceedings of the Foundation Analysis and Design, pp. 1-22, ASCE, Shanghai, China, June 2006.

[28] B. E. Sharnouby and M. Novak, "Stiffness constants and interaction factors for vertical response of pile groups," $\mathrm{Ca}$ nadian Geotechnical Journal, vol. 27, no. 6, pp. 813-822, 1990.

[29] P. H. Southcott and J. C. Small, "Finite layer analysis of vertically loaded piles and pile groups," Computers and Geotechnics, vol. 18, no. 1, pp. 47-63, 1996.
[30] G. Mylonakis and G. Gazetas, "Settlement and additional internal forces of grouped piles in layered soil," Géotechnique, vol. 48, no. 1, pp. 55-72, 1998.

[31] F. Basile, "Analysis and design of pile groups," in Numerical Analysis and Modelling in Geomechanics, J. W. Bull, Ed., pp. 278-315, CRC Press, Boca Raton, FL, USA, 2003.

[32] Y. F. Leung, K. Soga, B. M. Lehane, and A. Klar, "Role of linear elasticity in pile group analysis and load test interpretation," Journal of Geotechnical and Geoenvironmental Engineering, vol. 136, no. 12, pp. 1686-1694, 2010.

[33] J. H. Lee, Y. Kim, and S. Jeong, "Three-dimensional analysis of bearing behavior of piled raft on soft clay," Computers and Geotechnics, vol. 37, no. 1-2, pp. 103-114, 2010.

[34] M. Bryan and S. Bria, "Pile group settlement estimation: suitability of nonlinear interaction factors," International Journal of Geomechanics, vol. 15, no. 3, 2015.

[35] H. M. Algin, "Optimised design of jet-grouted rafts subjected to nonuniform vertical loading," KSCE Journal of Civil Engineering, vol. 22, no. 2, pp. 494-508, 2018.

[36] H. Moayedi and A. Rezaei, "An artificial neural network approach for under-reamed piles subjected to uplift forces in dry sand," Neural Computing and Applications, vol. 31, no. 2, pp. 327-336, 2019.

[37] H. Moayedi and S. Hayati, "Applicability of a CPT-based neural network solution in predicting load-settlement responses of bored pile," International Journal of Geomechanics, vol. 18, no. 6, 2018.

[38] S. P. Chen, W. J. Yao, and S. Q. Zhu, "Nonlinear finite element analysis of super-long pile and soil interaction in soft soil," Advanced Materials Research, vol. 201-203, pp. 1601-1605, 2011.

[39] T. Jiang, Three Dimensional Non-linear Finite Element Analysis of the Pile-Group Effect for Large-Diameter and Super-long Pile-Group Foundation, HoHai University, Nanjing, China, 2007, in Chinese.

[40] Ministry of Housing and Urban-Rural Development, JGJ94, Technical Code for Building Pile Foundations, Ministry of Housing and Urban-Rural Development, Beijing, China, 2008.

[41] Y. F. XIE and S. C. CHI, "Optimization method for irregular piled raft foundation on layered soil media," Advances in Civil Engineering, vol. 2019, Article ID 5713492, 15 pages, 2019. 